\title{
Extraction of permanent pacing leads: there are still controversies
}

Pacemaker lead extraction has been performed, by necessity, for many years but in limited numbers. This procedure has received increasing attention in recent years because of advances in extraction techniques ${ }^{12}$ and more recently the recall of the Accufix atrial J lead (Teletronics Pacing Systems, Englewood, Colorado). The procedure is not without serious risks, including death, and should not be undertaken lightly or without a thorough understanding of the procedure and its potential difficulties. Several aspects of lead extraction have yet to be clearly defined. Specifically, what are the absolute indications for lead extraction (including the Accufix lead), is there a preferred technique for lead extraction, and should there be training requirements for performing lead extractions?
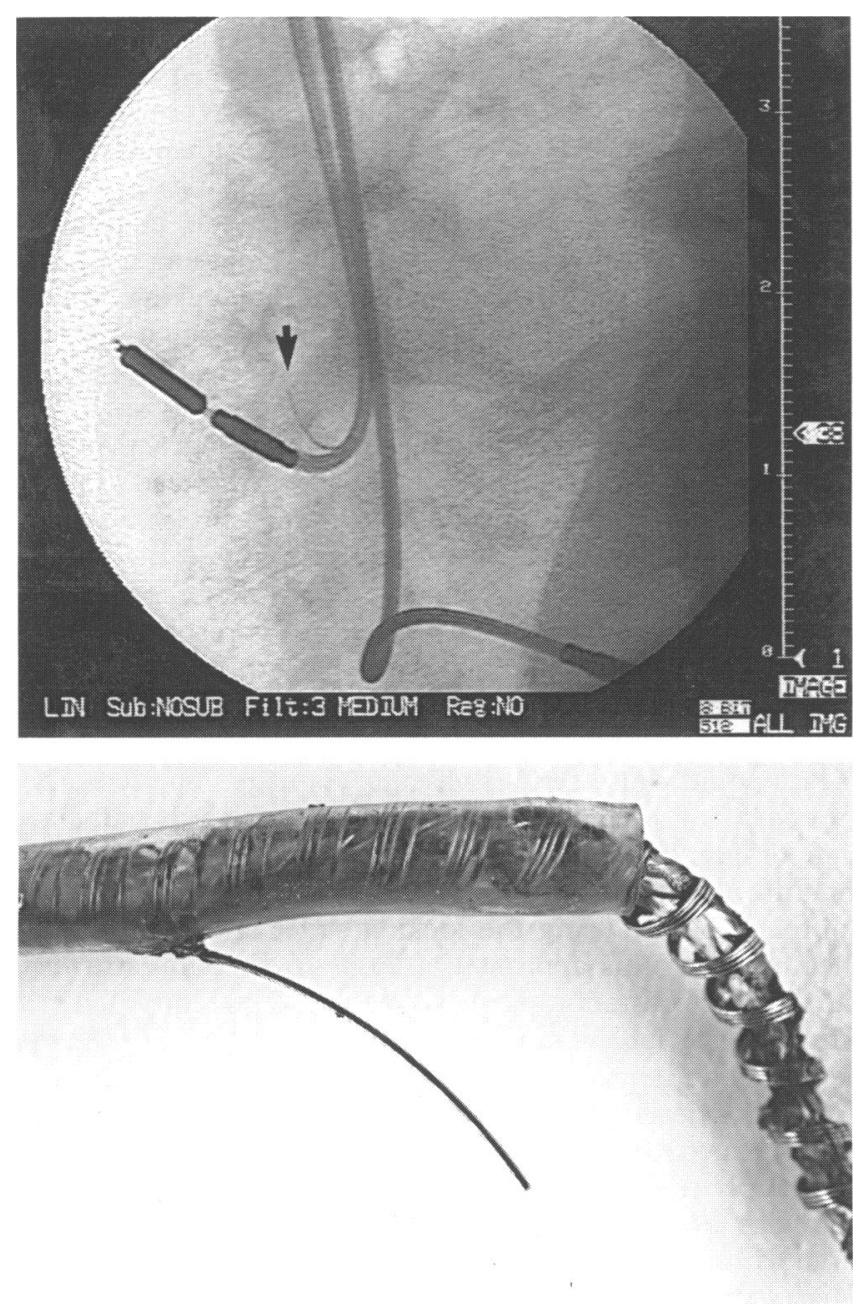

Figure 1 Fluoroscopic image (upper) of an Accufix lead showing a fractured and extruded retention wire (reprinted with permission from $M F, M c G o o n$ MD. Mayo Clin Proc 1996;71:230-4). A photograph of the extracted lead is shown below ${ }^{3}$ (reprinted with the permission of Futura Publishing).

\section{Indications}

Although there are some controversies regarding indications for lead extractions, absolute indications can be summarised easily. If the lead could harm the patient, its extraction should be considered. Infection of retained leads and mechanical complications are obvious indications, as is fracture or potential fracture of the Teletronics Accufix atrial J lead. ${ }^{3}$ Most of the multiple lead advisories issued in the past decade have been for leads with unacceptably high failure rates caused by insulation problems. Although these failed leads may have had to be abandoned and a new lead implanted it was usually not necessary to extract the defective lead. The recall of the Accufix atrial J lead differs significantly in that simply abandoning the lead and placing a new atrial lead does not protect the patient. ${ }^{3}$ The Accufix lead incorporates a small wire, the function of which is to retain the J shape of the lead. This wire can fracture. If the wire fractures and is extruded through the insulation it can lacerate the aorta or perforate the atrial myocardium, leading to fatal bleeding or cardiac tamponade. With deaths and other near catastrophic events documented as a result of this mechanism, a lead recall was issued. The recall and the nature of the recall has resulted in many Accufix leads being extracted. Subsequently, there have been multiple anecdotal reports of deaths caused by an attempt to extract the lead.

How then does one decide when to extract this particular lead? This has been the subject of considerable controversy and no consensus has been reached. Some have advocated the elective removal of all potentially defective Accufix leads. ${ }^{4}$ The decision to extract or not to extract must be made on an individual basis. Fluoroscopic techniques have been shown to be reliable in detecting retention wire fracture (fig 1). ${ }^{3}$ Patients with fluoroscopically normal leads can be followed serially by fluoroscopy and given appropriate counselling. If the wire is fractured but not extruded through the lead insulation, serial fluoroscopy also seems appropriate. If the wire is fractured and extruded, the potential risks and benefits of lead extraction should be discussed thoroughly with the patient and a clinical decision made. Before any extraction is attempted, whether of an Accufix or any other lead, it is imperative that the procedure, including all potential complications, be explained in detail to the patient.

\section{Personnel}

Who should perform the extraction once the decision has been made to extract a lead? It is clear from the extraction registry data ${ }^{5}$ that less experienced operators have a lower chance of a successful outcome, a higher incidence of complications, and a longer procedure time. The published guidelines for lead extraction are vague. ${ }^{6}$ They state that it is preferrable to have exposure to lead extraction techniques and if a trainee cannot learn such techniques 


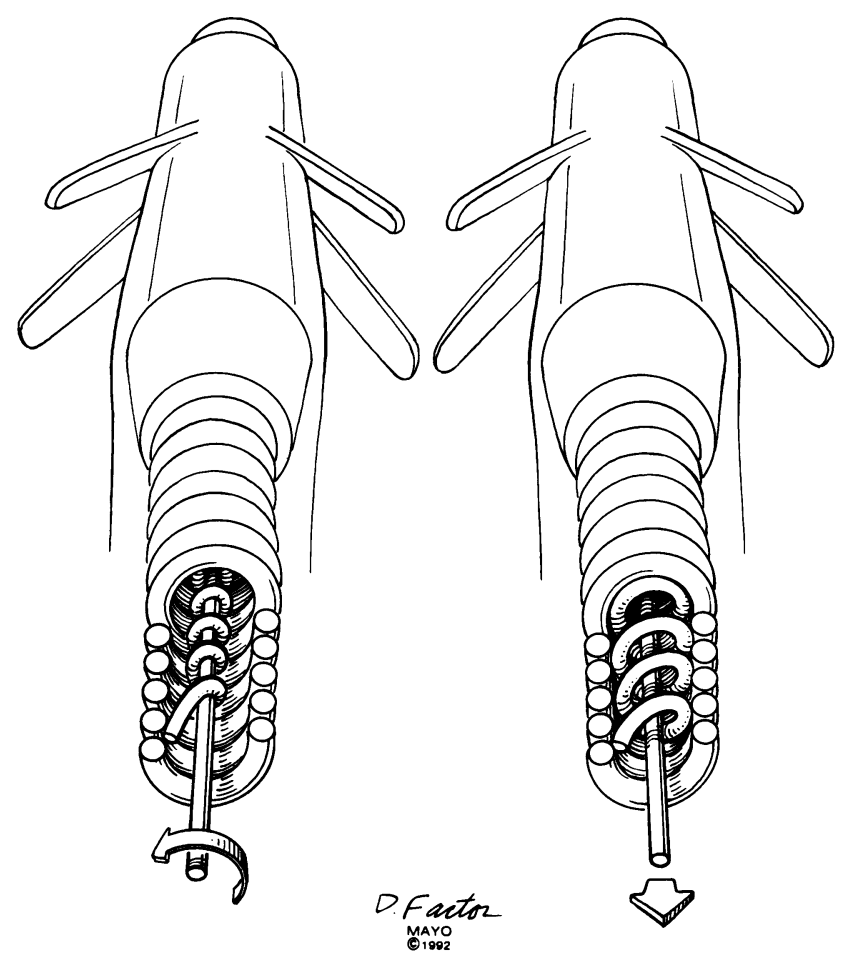

Figure 2 The locking stylet technique is based on the ability to grasp the coil with a locking guidewire so that traction can be applied at or near the tip of the lead. Left: The locking stylet is inserted and rotated. Right: Once the stylet is locked traction can be applied. (Reprinted from A Practice of Cardiac Pacing. S Furman, D L Hayes, $D R$ Holmes fr, eds. Mount Kisco NY:Futura Publishing, 1993;708).

during the training period and wishes to perform the procedure at a later date the experience should be sought with someone expert in extraction.

\section{Training}

The performance of lead extraction requires specialised training in a centre that performs the procedure frequently. The inexperienced physician who wishes to perform extractions has the following options. There are educational videotapes of excellent quality available that demonstrate the extraction equipment and how the various components are utilised. Although helpful, this does not prepare the operator for the myriad of variations and complications that may be present in an individual patient. Lead extraction is rarely, if ever, required as an emergency. For those physicians who are inadequately trained in lead extraction, a number of experienced centres welcome referral of the patient and attendance by the referring physician so that he or she can learn by observation. The final and logistically difficult option for practising physicians is to spend time at a centre that is experienced in performing lead extraction. Unfortunately few institutions perform extractions in sufficient numbers to provide a predictable experience in a finite period.

The potential morbidity of lead extraction is certainly greater than that associated with device implantation. ${ }^{5}$ As noted above, stringent guidelines for training requirements for pacemaker implantation are in place, but the guidelines for lead extraction are less precise. More rigorous guidelines for training requirements in lead extraction are needed-soon.

\section{Technique}

Which of the several endovascular approaches to lead extraction that have been described is the preferred approach? Individual operators have definite biases regarding technique - that is, superior approach with locking stylet with or without telescoping sheaths, femoral approach with snare technique, or Dotter retrieval technique. ${ }^{78} \mathrm{~A}$ few of the advantages and disadvantages of the various techniques warrant comment.

Simple traction minimises the need for special equipment, but without countertraction, aggressive traction may be more likely to result in an endocardial tear and may also stretch or break the lead. If the insulation separates from the lead leaving a bare uncoiling electrode, it may be difficult to employ other extraction techniques. The Cook extraction system may be employed in a superior or inferior approach. The superior approach is via the implanted lead. A locking stylet is sized to the lead that is to be extracted. After the locking stylet is introduced into the lead, counterclockwise rotation of the locking stylet results in the stylet being "locked" or caught or ensnared in the coil of the lead (fig 2). Use of the locking stylet is relatively straightforward and although the locking stylet alone does not provide countertraction, it does allow the force of traction to be directed to the point where the locking stylet is ensnared in the coil. This will ideally be at a position close to the endocardial surface. The locking stylet often allows the lead tip to be freed from the endocardial surface but fibrous adhesions along the vascular tree may still prevent extraction. The telescoping sheaths can be used to break-up these fibrous adhesions to the vascular wall and provide countertraction at the endocardial surface. Often the most difficult part of passing the telescoping sheaths is when a stainless steel dilator is passed under the clavicle. Once the initial subclavicular portion of the lead has been traversed the telescoping sheaths are used. These sheaths are made of nylon or polypropylene and come in various sizes to accommodate the lead to be extracted. First, a small sheath that is sized to fit around the lead is advanced under fluoroscopy. During any manipulation of the sheaths traction must be maintained on the locking stylet. A second larger sheath is advanced over the first sheath always keeping the smaller sheath on the leading edge. This telescoping forward movement is continued until the sheaths reach the endocardial surface, unless traction on the locking stylet results in withdrawal of the lead before the endocardial surface is reached-that is, it is possible that fibrous adhesions along the course of the lead that are now broken by the telescoping sheaths no longer impede extraction. Once the endocardial surface is reached countertraction can be maintained by the sheath while traction is applied to the locking stylet (fig 3). It must be remembered throughout this process that a misdirected dilator or sheath could cause serious vascular damage. The femoral approach is usually reserved for cases in which the subclavian or jugular approach has been unsuccessful. Some, including our institution, prefer to use the femoral approach before using the locking stylet and telescoping sheaths. With this approach, a large 16 French catheter, the Cook Workstation, is put in place via the femoral vein. Through this large catheter various extraction devices can be placed and manipulated. Some prefer a basket retriever (Dotter retriever) while others use a snare device to encircle the free tip of the lead or a loop of the pacing lead and then apply traction from below. A countertraction sheath may also be applied via the inferior approach. Placing a large catheter in the femoral vein is also not without risk. There could be local trauma to the femoral vein and the operator must constantly remember the length of time that various catheters, baskets, snares, etc., remain in place because of their potentially thrombogenic nature. As long as the operator has a thorough understanding of the equipment and options at his or her disposal, the extrac- 


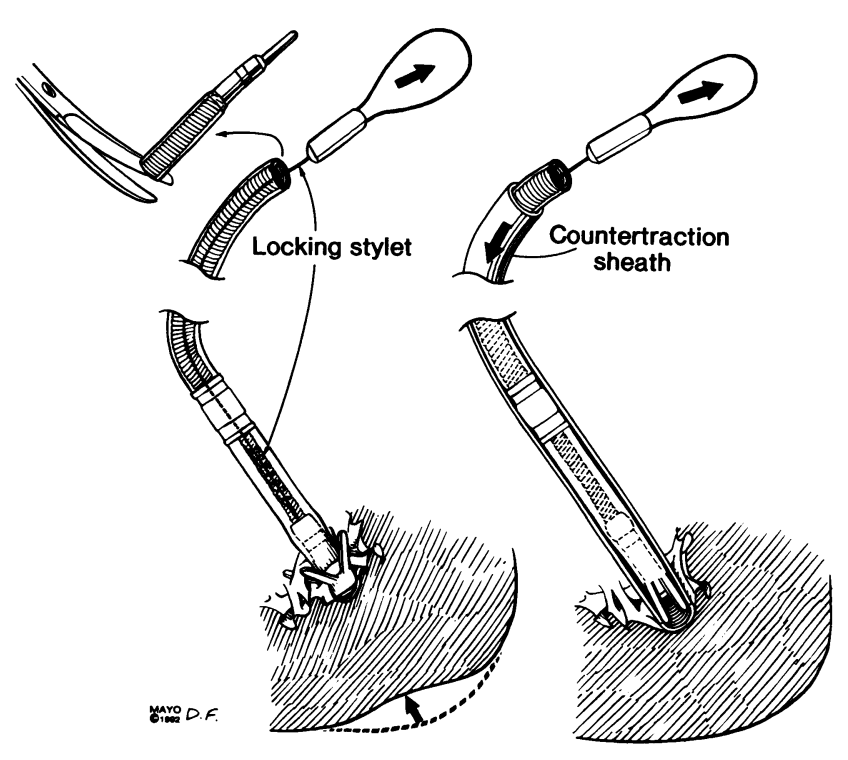

Figure 3 Left: After the connector has been cut from the lead and the locking stylet is sized and placed within the lead, traction is applied. Right: If traction with the locking stylet alone is not successful in removing the lead, the telescoping sheaths are placed over the lead and advanced to the endocardial surface if possible. This provides countertraction when direct traction is applied to the locking stylet. (Reprinted from A Practice of Cardiac Pacing. S Furman, D L Hayes, D R Holmes Fr eds. Mount Kisco NY:Futura Publishing, 1993:709).

tion method and approach should be defined by their comfort level and expertise.

A physician who is considering performing a percutaneous lead extraction should not overlook the possibility of surgical removal of leads. ${ }^{9}$ Although most leads can be extracted by a percutaneous technique, some cannot, and thoracotomy or some other limited surgical approach may be the best option for the patient. ${ }^{10}$
The next challenge in lead extraction will be the increasing requirement for experience in extraction of defibrillation leads. Endocardial leads that are currently part of implantable cardioverter defibrillator systems are, in general, larger in calibre and most are longer than standard pacing leads. These differences can add to the difficulty of the the extraction procedure.

Extraction techniques will undoubtedly continue to evolve and improve. For now and the foreseeable future this procedure must be approached with great respect by personnel who are committed to developing expertise. DAVID L HAYES

Division of Cardiovascular Diseases and Internal Medicine and the Department of Radiology,

Mayo Clinic,

Mayo Foundation,

Rochester,

Minnesota,

USA

1 Byrd CL, Schwartz SJ, Hedin NB, et al. Intravascular lead extraction using locking stylets and sheaths. PACE 1990;13:1871-5.

2 Byrd CL, Schwartz SJ, Hedin N. Intravascular techniques for extraction of Byrd CL, Schwartz SJ, Hedin N. Intravascular techniques for extraction of
permanent pacemaker leads. $\mathcal{F}$ Thorac Cardiovasc Surg 1991;101:989-97.

permanent pacemaker leads. $\mathcal{F}$ Thorac Cardiovasc Surg 1991;101:989-97.
3 Lloyd MA, Hayes DL, Holmes DR Jr. Atrial ' $J$ ' pacing lead retention wire fracture: radiographic assessment, incidence of fracture and clinical management. PACE 1995;18:958-64

4 Sulke N, Chambers J, Blauth C. Life-threatening degeneration of the Accufix active-fixation atrial-pacing electrode. Lancet 1995;346:25-6.

5 Smith HJ, Fearnot NE, Byrd CL, Wilkoff BL, Love CJ, Sellers D for the US Lead Extraction Database. Five-years experience with intravascular lead extraction. $P A C E$ 1994;17:2016-20.

6 Hayes DL, Naccarelli GV, Furman S, Parsonnet V, and the NASPE Pacemaker Training Policy Conference Group. Report of the NASPE policy conference training requirements for permanent pacemaker selection, implantation, and follow up. PACE 1994:17:6-12.

7 Espinosa RE, Hayes DL, Vlietstra RE, Osborn MJ, McGoon MD. The Dotter retriever and pigtail catheter: efficacy in extraction of chronic transvenous pacemaker leads. PACE 1993;16:2337-42.

8 Colavita PG, Zimmern SH, Gallagher JJ, Fedor JM, Austin WK, Smith HJ. Intravascular extraction of chronic pacemaker leads: efficacy and follow up. $P A C E$ 1993;16:2233-6.

9 Frame R, Brodman R, Furman S, Andrews C, Gross J. Surgical removal of infected transvenous pacemaker leads. $P A C E$ 1993;16:2243-8.

10 Belott PH, Byrd CL. Recent developments in pacemaker implantation and lead retrieval. In Barold SS, Mugica J, eds. New perspectives in cardiac pacing: Vol. 2. Mount Kisco, NY: Futura, 1991: 105-31. 